\title{
Differential effects of KRAS mutational status on long-term survival according to the timing of colorectal liver metastases
}

Nozomu Sakai, Katsunori Furukawa, Tsukasa Takayashiki, Satoshi Kuboki, Shigetsugu Takano and Masayuki Ohtsuka*

\begin{abstract}
Background: The relationship between KRAS mutational status and timing of colorectal liver metastasis (CRLM) remains unclear. This study evaluated the relationship between KRAS mutational status and long-term survival in patients with synchronous CRLM.

Methods: Of the 255 patients who underwent initial hepatic resection for CRLM between January 2001 and December 2018, the KRAS mutational status was examined in 101 patients. Medical records of these patients were reviewed to evaluate recurrence and survival outcomes.

Results: KRAS mutant status was identified in 38 patients (37.6\%). The overall survival (OS) was significantly better in patients with wild-type KRAS than in those with mutant KRAS status. In patients with synchronous metastases, the OS of patients with wild-type KRAS was significantly better than those with mutant KRAS. Multivariate analyses indicated shorter OS to be independently associated with positive primary lymph node, and large tumor size and $\mathrm{R} 1$ resection in patients with metachronous metastasis, whereas to be independently associated with mutant KRAS status in patients with synchronous metastasis. Furthermore, in the subgroup of patients with synchronous metastases, the repeat resection rate for hepatic recurrence was significantly high in those with wild type KRAS than in those with mutant KRAS.
\end{abstract}

Conclusion: KRAS mutation is an independent prognostic factor in patients with synchronous CRLM, but not in patients with metachronous CRLM.

Keywords: Colorectal cancer, Liver metastases, KRAS, Synchronous metastasis, Hepatectomy

\section{Introduction}

Colorectal cancer $(\mathrm{CRC})$ is one of the common causes of cancer-related mortality worldwide. Distant metastasis is strongly associated with poor prognosis in patients with CRC. During the course of CRC, colorectal liver metastases (CRLM) occur in approximately half of the patients [1]. Surgical resection is the primary treatment modality for CRLM, which ensures complete restoration or long-

\footnotetext{
* Correspondence: otsuka-m@faculty.chiba-u.jp

Department of General Surgery, Graduate School of Medicine, Chiba University, 1-8-1 Inohana, Chuo-ku, Chiba 260-8670, Japan
}

term survival in the patients. The 5-year OS rate in patients with CRLM after surgical resection is currently 33-51\% [1-3]. Historically, hepatic resection for CRLM was indicated for tumors isolated only in the liver with less aggressive features (i.e., low number, small size) [4]. However, the indication for hepatic resection for CRLM has been extended over the past decades to include more patients with aggressive disease features. Recent studies demonstrated that the presence of extrahepatic metastases is no longer a contraindication for surgical resection in patients with colorectal metastases [5-7]. In

(C) The Author(s). 2021 Open Access This article is licensed under a Creative Commons Attribution 4.0 International License, which permits use, sharing, adaptation, distribution and reproduction in any medium or format, as long as you give appropriate credit to the original author(s) and the source, provide a link to the Creative Commons licence, and indicate if changes were made. The images or other third party material in this article are included in the article's Creative Commons licence, unless indicated otherwise in a credit line to the material. If material is not included in the article's Creative Commons licence and your intended use is not permitted by statutory regulation or exceeds the permitted use, you will need to obtain permission directly from the copyright holder. To view a copy of this licence, visit http://creativecommons.org/licenses/by/4.0/ The Creative Commons Public Domain Dedication waiver (http://creativecommons.org/publicdomain/zero/1.0/) applies to the data made available in this article, unless otherwise stated in a credit line to the data. 
the past, one centimeter was considered an adequate surgical margin $[8,9]$. However, recent data have shown that a $1 \mathrm{~cm}$ margin is not a requisite for curative resection, and that margin width does not affect long-term survival $[10,11]$. One reason for these changes might be attributable to the use of perioperative chemotherapy with molecular targeted agents [12]. In fact, systemic chemotherapy has been evolving since the late 2000s, especially after the EPOC study [13]. Moreover, several randomized control trials demonstrated the clinical implication of KRAS mutational status and RAS mutational status is now commonly used as a determinant of antiEGFR antibody administration in modern chemotherapy regimens $[14,15]$.

Synchronous metastasis is associated with shorter disease-free survival duration and may correlate with the more disseminated disease than that with metachronous metastasis [16]. A recent nationwide survey in Japan demonstrated that adjuvant chemotherapy is associated with a favorable prognosis in patients with synchronous CRLM, but not in those with metachronous CRLM [17]. Another study suggested that adjuvant chemotherapy is more effective in cases with synchronous metastases than in those with metachronous metastases [18]. These data highlight the differences in tumor biology between synchronous and metachronous metastases. Recent studies have revealed that somatic mutations in genes such as KRAS and BRAF are associated with poor clinical outcomes in patients with CRLM [19-24]. Mutations in KRAS are found in about $30 \%$ of the patients with CRLM [20]. However, fewer studies have studied the association between the mutational status of KRAS and the timing of CRLM.

The aim of the present study was to evaluate the relationship between the mutational status of KRAS and long-term survival in patients with synchronous CRLM.

\section{Patients and methods Patients}

A total of 255 patients underwent initial hepatic resection for CRLM at the Department of General Surgery, Chiba University, between January 2001 and December 2018. Of these, the mutation status of KRAS was examined in 101 patients. The medical records of these consecutive patients were reviewed retrospectively. This study was approved by the Institutional Ethics Committee of the College of Medicine, Chiba University, Japan. Informed consent was obtained from all the patients after explaining the extent of the disease, and the benefits and risks associated with the treatments.

\section{Surgical procedure}

Pringle's maneuver was used, whenever possible, to decrease intraoperative bleeding from the cut surface of the liver. Transection of the liver parenchyma was performed in all patients using a cavitron ultrasonic surgical aspirator.

\section{KRAS mutation profiling}

DNA was extracted from the paraffin blocks of primary CRC or CRLM. Polymerase chain reaction (PCR)-based primer extension assay was performed to screen for genomic mutations encoding residues 12 and 13 of the KRAS protein.

\section{Definition of synchronous metastases}

Synchronous metastases was defined as the metastases that are clinically and/or radiologically detected when the primary cancer is diagnosed.

\section{Definition of surgical margin}

All the resected specimens were subjected to a routine pathological examination. The cases with $\mathrm{R} 1$ resection were identified based on microscopically incomplete resection with the presence of tumor invasion on the cut surface (i.e., a tumor-free margin of $0 \mathrm{~mm}$ ).

\section{Statistical analysis}

All data were retrospectively collected and differences were considered statistically significant at $P$-values < 0.05. Relationships between categorical variables were assessed using either the chi-square test or Fisher's exact test, as appropriate. Survival outcomes after the initial hepatectomy for CRLM were evaluated using the Kaplan-Meier method and log-rank test. Survival data were evaluated using univariate and multivariate Cox proportional regression analyses. All the statistical analyses were performed using the JMP Pro software (version 13; SAS Institute Japan, Tokyo, Japan).

\section{Results}

Patients' characteristics and perioperative data

The demographic and clinicopathological characteristics of patients are summarized in Table 1 . Of the $101 \mathrm{pa}$ tients, 63 (62.4\%) had wild-type KRAS status (KRAS-wt), whereas $38(37.6 \%)$ had mutant KRAS status (KRASmut). As indicated in Table 1 , there were no significant differences in patient characteristics based on the mutational status of KRAS.

\section{Oncological outcomes}

The 3-year recurrence-free survival (RFS) and 5-year OS rates were 14.9 and $41.2 \%$, respectively, for all the patients. In KRAS-wt patients, the median RFS was 11 months and the 3 -year RFS rate was $24.2 \%$. In KRASmut patients, the median RFS was 8 months and the 3year RFS rate was $8.2 \%$ (Fig. 1a). Further, in KRAS-wt patients, the median OS was 71 months and the 5-year 
Table 1 Patient characteristics

\begin{tabular}{|c|c|c|c|}
\hline \multicolumn{3}{|l|}{ Characteristics } & \multirow[t]{2}{*}{$P$-value } \\
\hline & $\begin{array}{l}\text { KRAS-wt }(n=63) \\
\mathrm{n}(\%)\end{array}$ & $\begin{array}{l}\text { KRAS-mut }(n=38) \\
\mathrm{n}(\%)\end{array}$ & \\
\hline Sex, male/female & $36 / 27(57.1 / 42.9)$ & $22 / 16(57.9 / 42.1)$ & 1.000 \\
\hline Median age (range) (years) & $66(33-83)$ & $69(35-82)$ & 0.821 \\
\hline \multicolumn{4}{|l|}{ Primary tumor } \\
\hline Right-sided/Left-sided/rectum & $11 / 31 / 21(17.5 / 49.2 / 33.3)$ & 7/18/13 (18.4/47.4/34.2) & 0.983 \\
\hline $\mathrm{pT} 1-3 / \mathrm{T} 4$ & $36 / 27(57.1 / 42.9)$ & $23 / 15(60.5 / 39.5)$ & 0.738 \\
\hline Node positive / node negative & 48/15 (76.2/23.8) & $30 / 8(78.9 / 21.1)$ & 0.811 \\
\hline \multicolumn{4}{|l|}{ Initial liver metastases } \\
\hline Synchronous / metachronous diagnosis & $34 / 29(54.0 / 46.0)$ & $22 / 16(57.9 / 42.1)$ & 0.837 \\
\hline Unilobar / bilobar & $36 / 27(57.1 / 42.9)$ & $18 / 20(47.4 / 52.6)$ & 0.412 \\
\hline Mean number of tumors, (range) & $3.7(1-26)$ & $3.6(1-19)$ & 0.910 \\
\hline Solitary / multiple metastases & $23 / 40(36.5 / 63.5)$ & $12 / 26(31.6 / 68.4)$ & 0.670 \\
\hline Largest tumor's mean size, cm, & $3.8(0.5-13)$ & $3.5(0.8-10)$ & 0.531 \\
\hline Serum carcinoembryonic antigen $(\mathrm{ng} / \mathrm{mL}),<5 / \geq 5$ & $17 / 46(27.0 / 73.0)$ & $13 / 25(34.2 / 65.8)$ & 0.503 \\
\hline Hepatectomy, minor/major & $43 / 20(68.3 / 31.8)$ & 27/11 (71.1/28.9) & 0.827 \\
\hline Surgical margin, R0/R1 & $44 / 19(69.8 / 30.2)$ & 26/12 (68.4/31.6) & 1.000 \\
\hline Preoperative chemotherapy, yes/no & $37 / 26(58.7 / 41.3)$ & $23 / 15(60.5 / 39.5)$ & 1.000 \\
\hline Adjuvant chemotherapy, yes/no & $41 / 22(65.1 / 34.9)$ & 25/13 (65.8/34.2) & 1.000 \\
\hline
\end{tabular}

OS rate was $50.1 \%$. In $K R A S$-mut patients, the median OS was 36 months and the 5 -year OS rate was $26.8 \%$ (Fig. 2a). There was no significant difference between RFS for KRAS-wt and KRAS-mut patients $(P=0.139)$. Whereas the OS rate was found to be significantly better in patients with $K R A S$-wt than in those with KRAS-mut status $(P=0.021)$. Next, in the subgroup analysis, RFS was not significantly different based on the KRAS mutational status in patients with metachronous metastases (3-year RFS rates and median RFS: $21.5 \%$ and 11 months in KRAS-wt, while $18.8 \%$ and 10 months in KRAS-mut patients, respectively; $P=0.567$ ) (Fig. 1b). In patients with synchronous metastases, the RFS of KRAS-wt patients was relatively better, but not significant, than those with KRAS-mut status (3-year RFS rate and median RFS: $27.4 \%$ and 11 months in patients with $K R A S$ wt, and $0.0 \%$ and 10 months in those with KRAS-mut status, respectively; $P=0.076$ ) (Fig. $1 \mathrm{c}$ ). The $\mathrm{OS}$ was not significantly different based on the KRAS mutational status in patients with metachronous metastases (5-year OS rate and median OS: $36.8 \%$ and 50 months in KRAS-wt versus $45.3 \%$ and 58 months in KRAS-mut; $P=0.294$ )

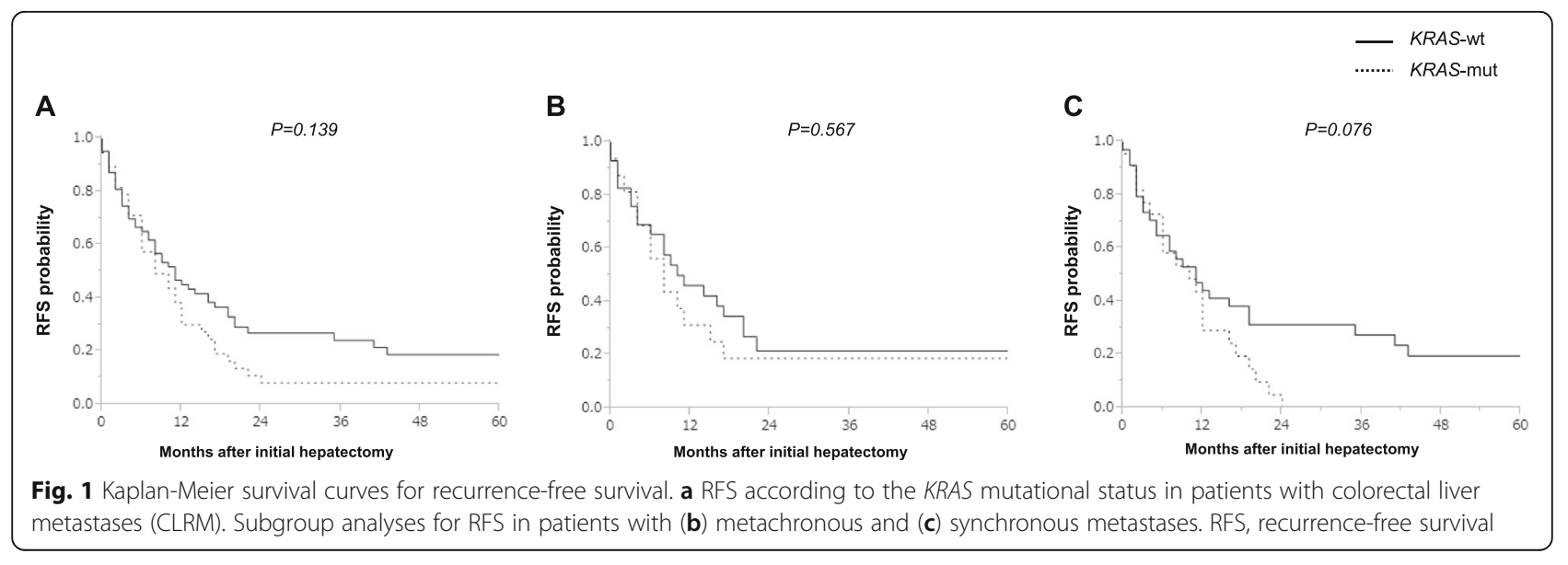




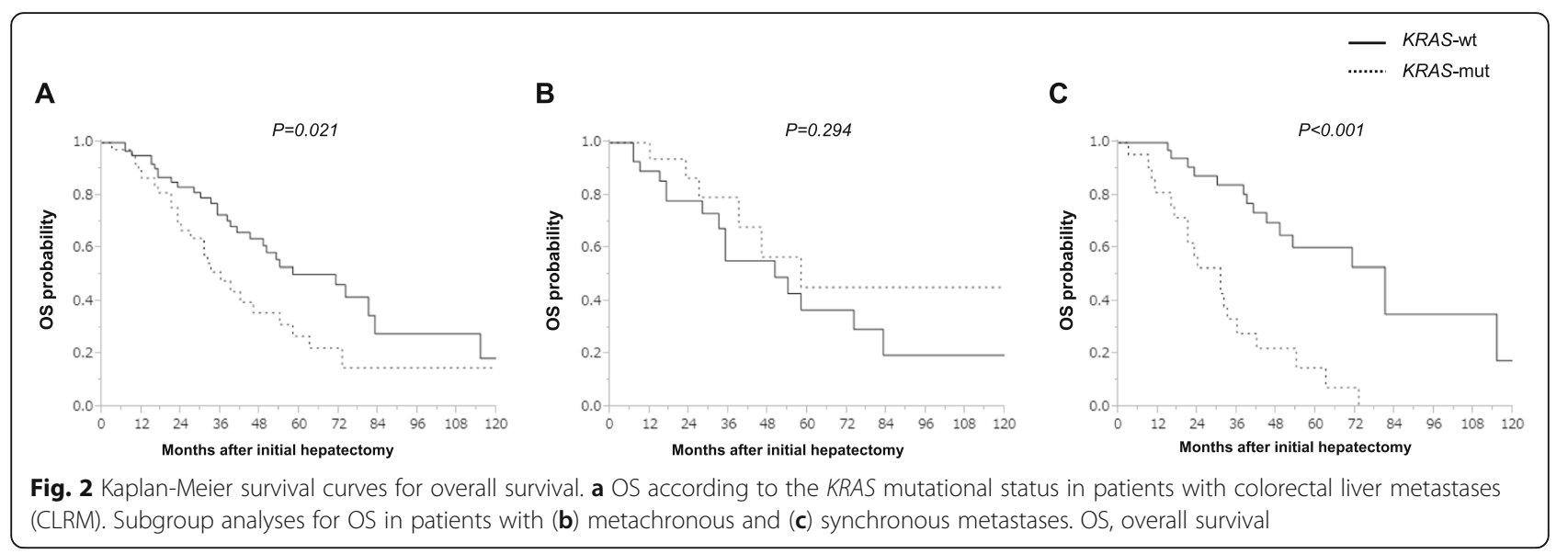

(Fig. 2b). Whereas, the OS of patients with synchronous metastases harboring KRAS-wt was significantly better than those harboring KRAS-mut status (5-year OS rate and median OS: $60.4 \%$ and 81 months in KRAS-wt versus $14.9 \%$ and 31 months in KRAS-mut; $P<0.001$ ) (Fig. 2c). Furthermore, the univariate analyses revealed that shorter OS duration in patients was associated with synchronous metastasis $(P=0.050)$, bilobar tumor distribution $(P=0.005)$, increased number of tumors $(P=0.001)$, large tumor size $(\geq 5 \mathrm{~cm}, P<0.001)$, high serum carcinoembryonic antigen levels $(\geq 5 \mathrm{ng} / \mathrm{mL}, P=0.029)$, major hepatectomy $(P=0.002)$, R1 resection $(P=0.002)$, and mutant KRAS $(P=0.026)$ (Table 2). In multivariate analyses, shorter OS duration in patients was found to independently associate with $\mathrm{R} 1$ resection (hazard ratio [HR]: 2.554, $P=0.003$ ), and mutant KRAS status (HR: $2.409, P=0.003$ ) (Table 2). In patients with metachronous metastasis, shorter OS duration was found to be independently associated with positive primary lymph node (HR: $1.779, P=0.039)$, large tumor size $(\geq 5 \mathrm{~cm}$,

Table 2 Predictive factors of shorter OS ( $n=101)$

\begin{tabular}{|c|c|c|c|c|c|}
\hline Variables & $\begin{array}{l}\text { Univariate } \\
\text { analysis }\end{array}$ & & $\begin{array}{l}\text { Multivariate } \\
\text { analysis }\end{array}$ & & \\
\hline & $\mathrm{HR}$ & $P$-value & $H R$ & $95 \% \mathrm{Cl}$ & $P$-value \\
\hline Sex, male & 1.209 & 0.282 & & & \\
\hline Age & 1.007 & 0.344 & & & \\
\hline \multicolumn{6}{|l|}{ Primary tumor } \\
\hline Location, colon/rectum & 0.888 & 0.503 & & & \\
\hline Location, right-sided/left-sided & 0.818 & 0.385 & & & \\
\hline pT stage & 1.274 & 0.092 & & & \\
\hline Positive lymph node & 1.426 & 0.062 & & & \\
\hline \multicolumn{6}{|l|}{ Initial liver metastases } \\
\hline Timing of diagnosis: synchronous & 1.405 & 0.050 & 1.186 & $0.669-2.144$ & 0.562 \\
\hline Tumor distribution: bilobar & 1.642 & 0.005 & 1.106 & $0.594-2.103$ & 0.752 \\
\hline No. of tumors & 1.072 & 0.001 & & & \\
\hline No. of tumors (solitary/multiple): multiple & 2.050 & $<0.001$ & 1.010 & $0.523-2.436$ & 0.807 \\
\hline Tumor size $\geq 5 \mathrm{~cm}$ & 2.122 & $<0.001$ & 1.092 & $0.541-2.125$ & 0.801 \\
\hline Serum carcinoembryonic antigen $\geq 5 \mathrm{ng} / \mathrm{mL}$ & 1.586 & 0.029 & 1.964 & $0.991-4.188$ & 0.053 \\
\hline Type of hepatectomy: major & 1.812 & 0.002 & 1.415 & $0.762-2.586$ & 0.268 \\
\hline Surgical margin: R1 & 1.805 & 0.002 & 2.554 & $1.385-4.750$ & 0.003 \\
\hline KRAS mutational status: KRAS-mut & 1.860 & 0.026 & 2.409 & $1.361-4.250$ & 0.003 \\
\hline
\end{tabular}

HR Hazard ratio; Cl Confidence interval 
Table 3 Predictive factors of shorter OS (metachronous) $(n=45)$

\begin{tabular}{|c|c|c|c|c|c|}
\hline Variables & $\begin{array}{l}\text { Univariate } \\
\text { analysis }\end{array}$ & & Multivariate analysis & & \\
\hline & $\mathrm{HR}$ & $P$-value & $\mathrm{HR}$ & $95 \% \mathrm{Cl}$ & $P$-value \\
\hline Sex, male & 1.060 & 0.824 & & & \\
\hline Age & 1.119 & 0.854 & & & \\
\hline \multicolumn{6}{|l|}{ Primary tumor } \\
\hline Location, colon/rectum & 1.035 & 0.899 & & & \\
\hline Location, right-sided/left-sided & 0.784 & 0.473 & & & \\
\hline pT stage & 1.204 & 0.350 & & & \\
\hline Positive lymph node & 1.756 & 0.042 & 1.779 & $1.028-3.223$ & 0.039 \\
\hline \multicolumn{6}{|l|}{ Initial liver metastases } \\
\hline Tumor distribution: bilobar & 1.256 & 0.420 & & & \\
\hline No. of tumors & 1.053 & 0.127 & & & \\
\hline No. of tumors (solitary/multiple): multiple & 1.489 & 0.123 & & & \\
\hline Tumor size $\geq 5 \mathrm{~cm}$ & 3.023 & $<0.001$ & 3.010 & $1.734-5.131$ & $<0.001$ \\
\hline Serum carcinoembryonic antigen $\geq 5 \mathrm{ng} / \mathrm{mL}$ & 2.075 & 0.023 & 1.701 & $0.882-3.612$ & 0.117 \\
\hline Type of hepatectomy: major & 1.377 & 0.328 & & & \\
\hline Surgical margin: R1 & 1.898 & 0.034 & 2.060 & $1.122-3.632$ & 0.021 \\
\hline KRAS mutational status: KRAS-mut & 0.608 & 0.289 & & & \\
\hline
\end{tabular}

HR Hazard ratio; CI Confidence interval

Table 4 Predictive factors of shorter OS (synchronous) $(n=56)$

\begin{tabular}{|c|c|c|c|c|c|}
\hline Variable & $\begin{array}{l}\text { Univariate } \\
\text { analysis }\end{array}$ & & Multivariate analysis & & \\
\hline & $\mathrm{HR}$ & $P$-value & $\mathrm{HR}$ & $95 \% \mathrm{Cl}$ & $P$-value \\
\hline Sex, male & 1.421 & 0.139 & & & \\
\hline Age & 1.016 & 0.133 & & & \\
\hline \multicolumn{6}{|l|}{ Primary tumor } \\
\hline Location, colon/rectum & 0.783 & 0.303 & & & \\
\hline Location, right-sided/left-sided & 0.818 & 0.529 & & & \\
\hline pT stage & 1.232 & 0.344 & & & \\
\hline Positive lymph node & 1.083 & 0.765 & & & \\
\hline \multicolumn{6}{|l|}{ Initial liver metastases } \\
\hline Tumor distribution: bilobar & 1.857 & 0.009 & 1.312 & $0.562-3.138$ & 0.530 \\
\hline No. of tumors & 1.081 & 0.006 & 1.063 & $0.961-1.164$ & 0.223 \\
\hline No. of tumors (solitary/multiple): multiple & 2.930 & $<0.001$ & 0.920 & $0.298-3.230$ & 0.890 \\
\hline Tumor size $\geq 5 \mathrm{~cm}$ & 1.511 & 0.117 & & & \\
\hline Serum carcinoembryonic antigen $\geq 5 \mathrm{ng} / \mathrm{mL}$ & 1.205 & 0.514 & & & \\
\hline Type of hepatectomy: major & 1.976 & 0.005 & 1.221 & $0.535-2.765$ & 0.632 \\
\hline Surgical margin: R1 & 1.641 & 0.047 & 1.718 & $0.740-3.887$ & 0.202 \\
\hline KRAS mutational status: KRAS-mut & 4.517 & $<0.001$ & 4.316 & $1.973-9.845$ & $<0.001$ \\
\hline
\end{tabular}


Table 5 Recurrence after initial hepatectomy

\begin{tabular}{llll}
\hline & $\begin{array}{l}\text { KRAS-wt } \\
\boldsymbol{n = 6 3}\end{array}$ & $\begin{array}{l}\text { KRAS-mut } \\
\boldsymbol{n = 3 8}\end{array}$ & $\boldsymbol{P}$-value \\
\hline Total cohort & $49 / 63(77.8 \%)$ & $33 / 38(86.8 \%)$ & 0.304 \\
Synchronous metastases & $26 / 34(76.5 \%)$ & $20 / 22(90.9 \%)$ & 0.285 \\
Metachronous metastases & $23 / 29(79.3 \%)$ & $13 / 16(81.3 \%)$ & 1.000 \\
\hline
\end{tabular}

HR: 3.010, $P<0.001$ ), and R1 resection (HR: 2.060, $P=$ 0.021 ) (Table 3 ). In patients with synchronous metastasis, shorter OS duration was found to independently associate with mutant KRAS status (HR: 4.316, $P<0.001$ ) (Table 4).

\section{Recurrence after initial hepatectomy}

Disease recurrence after the initial hepatectomy was observed in 82 patients $(81.2 \%)$. There was an insignificant difference in recurrence rates between patients with $K R A S$-wt and KRAS-mut status $(77.8 \%$ vs. $86.8 \%)$ (Table 5). Repeat resection was performed in 25 (51.0\%) and $15(45.5 \%)$ patients with KRAS-wt and KRAS-mut status, respectively $(P=0.658$ ) (Table 6). In the subgroup of synchronous metastases, the repeat resection rate for all recurrence was $57.7 \%$ in patients with $K R A S$-wt and $30.0 \%$ in those with $K R A S$-mut status $(P=0.079)$ (Table 6). Hepatic recurrence was observed in $26(41.3 \%)$ and $23(60.5 \%)$ patients with $K R A S$-wt and KRAS-mut status, respectively $(P=0.068)$ (Table 7$)$. Repeat hepatectomy was performed in $15(57.7 \%)$ and $8(34.8 \%)$ patients with $K R A S$-wt and KRAS-mut status, respectively $(P=0.154)$ (Table 8 ). Whereas, in the subgroup of synchronous metastases, the repeat resection rate for hepatic recurrence was $66.7 \%$ in patients with $K R A S$-wt and $14.3 \%$ in those with $K R A S$-mut status $(P=0.008)$ (Table 8$)$. Repeat hepatectomy was not recommended in patients with synchronous metastases harboring KRAS-mut status due to multiple hepatic recurrence in 3 patients, and both hepatic and extrahepatic recurrence to the lung, peritoneal dissemination and bone in 9 patients. Of these, 9 patients developed recurrence within 12 months after initial hepatectomy. Moreover, extrahepatic recurrence (including both extrahepatic and hepatic recurrences) was observed in $18(68.2 \%)$ and 15 patients (52.9\%) with

Table 6 Repeat resection for all recurrence after initial hepatectomy

\begin{tabular}{llll}
\hline & $\begin{array}{l}\text { KRAS-wt } \\
\boldsymbol{n}=\mathbf{4 9}\end{array}$ & $\begin{array}{l}\text { KRAS-mut } \\
\boldsymbol{n}=\mathbf{3 3}\end{array}$ & $\boldsymbol{P}$-value \\
\hline Total cohort & $25 / 49(51.0 \%)$ & $15 / 33(45.5 \%)$ & 0.658 \\
Synchronous metastases & $15 / 26(57.7 \%)$ & $6 / 20(30.0 \%)$ & 0.079 \\
Metachronous metastases & $10 / 23(43.5 \%)$ & $9 / 13(69.2 \%)$ & 0.177 \\
\hline
\end{tabular}

Table 7 Hepatic recurrence after initial hepatectomy

\begin{tabular}{llll}
\hline & $\begin{array}{l}\text { KRAS-wt } \\
\boldsymbol{n}=\mathbf{6 3}\end{array}$ & $\begin{array}{l}\text { KRAS-mut } \\
\boldsymbol{n}=\mathbf{3 8}\end{array}$ & $\boldsymbol{P}$-value \\
\hline Total cohort & $26 / 63(41.3 \%)$ & $23 / 38(60.5 \%)$ & 0.068 \\
Synchronous metastases & $15 / 34(44.1 \%)$ & $14 / 22(63.6 \%)$ & 0.180 \\
Metachronous metastases & $11 / 29(37.9 \%)$ & $9 / 16(56.3 \%)$ & 0.348 \\
\hline
\end{tabular}

synchronous metastases harboring KRAS-wt and KRASmut status, respectively $(P=0.282)$.

\section{Discussion}

We aimed to delineate the relationship between $K R A S$ mutational status and long-term survival in patients with CRLM, and assess whether there were any differences in the effect of KRAS mutational status on the disease outcome based on the timing of metastasis. The present study clearly demonstrated that the effect of the mutation status of $K R A S$ varied according to the timing of liver metastasis. The KRAS-mut status was significantly associated with poor prognosis in patients with synchronous metastasis, but not in those with metachronous metastasis.

The reason for poor prognosis in patients with synchronous metastasis and KRAS-mut tumors may be partially explained by the recurrence patterns after initial hepatectomy. As reported previously, repeat hepatectomy for hepatic recurrence can yield survival benefit similar to that after initial hepatectomy [25]. Therefore, tumor recurrence itself is not always associated with poor prognosis, although unresectable recurrence is considered a distinct poor prognostic factor [26-28]. We found that the rate of re-resection for hepatic recurrence was significantly low in patients with synchronous metastases and KRAS-mut tumors, which might lead to poor prognosis in these patients than in those with synchronous metastases and KRAS-wt tumors.

Moreover, the rate of extrahepatic recurrence was relatively high in patients with synchronous metastases and $K R A S$-mut tumors than in those with synchronous metastases and KRAS-wt tumors. Since extrahepatic metastasis is also known to be associated with poor prognosis [6], this trend may affect the poor prognosis in patients.
Table 8 Repeat hepatectomy for hepatic recurrence after initial hepatectomy

\begin{tabular}{llll}
\hline & $\begin{array}{l}\text { KRAS-wt } \\
\boldsymbol{n}=\mathbf{2 6}\end{array}$ & $\begin{array}{l}\text { KRAS-mut } \\
\boldsymbol{n}=\mathbf{2 3}\end{array}$ & $\boldsymbol{P}$-value \\
\hline Total cohort & $15 / 26(57.7 \%)$ & $8 / 23(34.8 \%)$ & 0.154 \\
Synchronous metastases & $10 / 15(66.7 \%)$ & $2 / 14(14.3 \%)$ & 0.008 \\
Metachronous metastases & $5 / 11(45.5 \%)$ & $6 / 9(66.7 \%)$ & 0.406 \\
\hline
\end{tabular}


Another reason could be the difference in response to systemic chemotherapy according to the KRAS mutation status. In the context of systemic chemotherapy, Mise et al. investigated the association between RAS mutational status and response to preoperative chemotherapy in patients with CRLM. They revealed that RAS mutations were significantly associated with minor pathological and suboptimal morphological responses, which were assessed using computed tomographic scans [29]. Other studies also demonstrated that KRAS mutations were significantly associated with minor response to chemotherapy in patients with CRLM, and that RAS mutation status may serve as a biomarker for response to chemotherapy [29-31]. In the present study, the effect of perioperative chemotherapy was not assessed since various treatment regimens were used during the extended study period. However, preoperative and adjuvant chemotherapy were administered to almost $60 \%$ of the patients. Therefore, the variable responses to chemotherapy may lead to prognostic differences observed in the present study. Moreover, about $70 \%$ of the patients with synchronous metastases and KRAS-mut tumors received perioperative chemotherapy. Despite the high rate of administering chemotherapy, a poor prognosis was observed in this subgroup, suggesting that unfavorable response to chemotherapy may have resulted in disseminated and/or unresectable recurrences.

Other than the KRAS mutation status, the univariate and multivariate analyses revealed several differences between synchronous and metachronous metastases in terms of clinicopathological factors associated with patients' prognoses. In the context of the timing of metastasis, Tsai et al. demonstrated that synchronous metastasis was significantly associated with low diseasefree survival, and proposed that it may represent a highly disseminated disease than that with metachronous metastasis [16]. Additionally, other studies have demonstrated that response to chemotherapy may vary with the timing of metastasis $[18,32]$. Together, these results support the hypothesis that tumor biology may be influenced by the timing of metastasis. However, further studies would be required to ascertain the role of mutational statuses influencing the biological differences according to the timing of metastases.

Here, surgical margin status was not found to be a prognostic factor of synchronous metastasis. The clinical significance of surgical margin has been debated in past decades. Moreover, it has been reported that the extent of optimal tumor-free margin may vary according to the KRAS mutation status [33], with 1-4 mm margins being considered sufficient in patients with wild-type $K R A S$, whereas $1-\mathrm{cm}$ margins being considered insufficient for those with mutant KRAS status. Furthermore, other studies reported that the KRAS mutation status was associated with a narrow width of surgical margin [34, 35]. We defined R1 resection as microscopically incomplete resection with the presence of tumor invasion at the cut surface without considering margin width. Additionally, in all cases, parenchymal transection was performed using the cavitron ultrasonic surgical aspirator, which is known to ablate or aspirate parenchyma along the transection plane $[36,37]$. Therefore, there may be a certain number of patients who were inappropriately categorized on the basis of surgical margin status and our definition may have failed to stratify R0 and R1 resection, especially in patients with synchronous metastasis.

The present study has several limitations. First, the data were retrospectively collected from the database at a single center and comprised a small sample size. Second, the background data of the patients were not synchronized, indicating that selection bias may exist and affect the RFS and OS. Third, while the mutation status of KRAS was assessed, the differential effect of codons 12 and 13 was not considered. Moreover, somatic mutations in other genes such as NRAS and BRAF were examined only in a few patients and were not analyzed in the present study. Therefore, further studies should be conducted to assess the relationship of somatic mutations in multiple genes, such as KRAS, NRAS, and BRAF, with the clinical outcome of patients with CRLM.

\section{Conclusion}

In conclusion, our study found KRAS mutational status as an independent prognostic factor in patients with synchronous CRLM, but not in those with metachronous CRLM. We propose that the treatment strategy should be planned on the basis of the timing of metastasis, considering its influence on the biological behavior of CRLM.

\section{Acknowledgments \\ Not applicable.}

Authors' contributions

Study design: Sakai N., Ohtsuka M. Data acquisition: Sakai N. Analysis and interpretation: Sakai N., Furukawa K., Takayashiki T., Kuboki S., Takano S. Drafting of the manuscript: Sakai N. Critical revision of the manuscript: Furukawa K., Otsuka M. Final approval for the publication: all authors.

\section{Funding}

None

Availability of data and materials

The datasets used during this study are available from the corresponding author on reasonable request.

\section{Declarations}

\section{Ethics approval and consent to participate}

This study was approved by the Institutional Review Board of Chiba University (approval number 3300) and was performed according to the ethical principles of the Declaration of Helsinki. Informed consent was obtained from all the patients after explaining the extent of the disease, and the benefits and risks associated with the treatments. 


\section{Consent for publication}

Not applicable.

\section{Competing interests}

The authors declare that they have no competing interests.

\section{Received: 25 January 2021 Accepted: 30 March 2021}

Published online: 15 April 2021

\section{References}

1. Zaydfudim VM, McMurry TL, Harrigan AM, Friel CM, Stukenborg GJ, Bauer TW, et al. Improving treatment and survival: a population-based study of current outcomes after a hepatic resection in patients with metastatic colorectal cancer. HPB (Oxford). 2015;17(11):1019-24. https://doi.org/1 $0.1111 / \mathrm{hpb} .12488$

2. Engstrand J, Nilsson H, Stromberg C, Jonas E, Freedman J. Colorectal cancer liver metastases - a population-based study on incidence, management and survival. BMC Cancer. 2018;18(1):78. https://doi.org/10.1186/s12885-017-3925-X.

3. House MG, Ito $\mathrm{H}$, Gonen M, Fong $Y$, Allen PJ, DeMatteo RP, et al. Survival after hepatic resection for metastatic colorectal cancer: trends in outcomes for 1,600 patients during two decades at a single institution. J Am Coll Surg. 2010;210(5):744-52, 52-5. https://doi.org/10.1016/j.jamcollsurg.2009.12.040.

4. Pawlik TM, Schulick RD, Choti MA. Expanding criteria for resectability of colorectal liver metastases. Oncologist. 2008;13(1):51-64. https://doi.org/10.1 634/theoncologist.2007-0142

5. Elias $D$, Sideris $L$, Pocard M, Ouellet JF, Boige $V$, Lasser $P$, et al. Results of R0 resection for colorectal liver metastases associated with extrahepatic disease. Ann Surg Oncol. 2004;11(3):274-80. https://doi.org/10.1245/ASO.2 004.03.085.

6. Leung U, Gonen M, Allen PJ, Kingham TP, RP DM, Jarnagin WR, et al. Colorectal cancer liver metastases and concurrent extrahepatic disease treated with resection. Ann Surg. 2017;265(1):158-65. https://doi.org/10.1 097/SLA.0000000000001624.

7. Sawada Y, Sahara K, Endo I, Sakamoto K, Honda G, Beppu T, et al. Longterm outcome of liver resection for colorectal metastases in the presence of extrahepatic disease: a multi-institutional Japanese study. J Hepatobiliary Pancreat Sci. 2020;27(11):810-8. https://doi.org/10.1002/jhbp.810.

8. Elias D, Cavalcanti A, Sabourin JC, Lassau N, Pignon JP, Ducreux M, et al. Resection of liver metastases from colorectal cancer: the real impact of the surgical margin. Eur J Surg Oncol. 1998;24(3):174-9. https://doi.org/10.1016/ S0748-7983(98)92878-5.

9. Adams RB, Langer B. Resection margins for colorectal metastases to the liver: do they make a difference? HPB Surg. 1996;9(2):115-7. https://doi.org/1 $0.1155 / 1996 / 95180$.

10. Lordan JT, Karanjia ND. Size of surgical margin does not influence recurrence rates after curative liver resection for colorectal cancer liver metastases (Br J Surg 2007; 94: 1133-1138). Br J Surg. 2008;95(1):128-9. author reply 9. https://doi.org/10.1002/bjs.6124.

11. Muratore A, Ribero D, Zimmitti G, Mellano A, Langella S, Capussotti L. Resection margin and recurrence-free survival after liver resection of colorectal metastases. Ann Surg Oncol. 2010;17(5):1324-9. https://doi.org/1 0.1245/s10434-009-0770-4

12. Liu W, Zhou JG, Sun $Y$, Zhang $L$, Xing BC. The role of neoadjuvant chemotherapy for resectable colorectal liver metastases: a systematic review and meta-analysis. Oncotarget. 2016;7(24):37277-87. https://doi.org/10.1 8632/oncotarget.8671.

13. Nordlinger B, Sorbye H, Glimelius B, Poston GJ, Schlag PM, Rougier P, et al. Perioperative chemotherapy with FOLFOX4 and surgery versus surgery alone for resectable liver metastases from colorectal cancer (EORTC intergroup trial 40983): a randomised controlled trial. Lancet. 2008; 371(9617):1007-16. https://doi.org/10.1016/S0140-6736(08)60455-9.

14. Folprecht G, Gruenberger T, Bechstein WO, Raab HR, Lordick F, Hartmann JT, et al. Tumour response and secondary resectability of colorectal liver metastases following neoadjuvant chemotherapy with cetuximab: the CELI M randomised phase 2 trial. Lancet Oncol. 2010;11(1):38-47. https://doi. org/10.1016/S1470-2045(09)70330-4

15. Nordlinger B, Van Cutsem E, Gruenberger T, Glimelius B, Poston G, Rougier $P$, et al. European colorectal metastases treatment $G$, sixth international colorectal liver metastases $\mathrm{W}$. combination of surgery and chemotherapy and the role of targeted agents in the treatment of patients with colorectal liver metastases: recommendations from an expert panel. Ann Oncol. 2009; 20(6):985-92. https://doi.org/10.1093/annonc/mdn735.

16. Tsai MS, Su YH, Ho MC, Liang JT, Chen TP, Lai HS, et al. Clinicopathological features and prognosis in resectable synchronous and metachronous colorectal liver metastasis. Ann Surg Oncol. 2007;14(2):786-94. https://doi. org/10.1245/s10434-006-9215-5.

17. Kobayashi S, Beppu T, Honda G, Yamamoto M, Takahashi K, Endo I, et al. Survival benefit of and indications for adjuvant chemotherapy for resected colorectal liver metastases-a Japanese Nationwide survey. J Gastrointest Surg. 2020;24(6):1244-60. https://doi.org/10.1007/s11605-019-04250-9.

18. Hasegawa K, Saiura A, Takayama T, Miyagawa S, Yamamoto J, ljichi M, et al. Adjuvant Oral uracil-Tegafur with Leucovorin for colorectal Cancer liver metastases: a randomized controlled trial. PLoS One. 2016;11(9):e0162400. https://doi.org/10.1371/journal.pone.0162400.

19. Nash GM, Gimbel M, Shia J, Nathanson DR, Ndubuisi Ml, Zeng ZS, et al. KRAS mutation correlates with accelerated metastatic progression in patients with colorectal liver metastases. Ann Surg Oncol. 2010;17(2):572-8. https://doi.org/10.1245/s10434-009-0605-3.

20. Karagkounis G, Torbenson MS, Daniel HD, Azad NS, Diaz LA Jr, Donehower $\mathrm{RC}$, et al. Incidence and prognostic impact of KRAS and BRAF mutation in patients undergoing liver surgery for colorectal metastases. Cancer. 2013; 119(23):4137-44. https://doi.org/10.1002/cncr.28347.

21. Vauthey JN, Zimmitti G, Kopetz SE, Shindoh J, Chen SS, Andreou A, et al. RAS mutation status predicts survival and patterns of recurrence in patients undergoing hepatectomy for colorectal liver metastases. Ann Surg. 2013; 258(4):619-26; discussion 26-7. https://doi.org/10.1097/SLA.0b013e3182a5025a.

22. Schirripa M, Cremolini C, Loupakis F, Morvillo M, Bergamo F, Zoratto F, et al. Role of NRAS mutations as prognostic and predictive markers in metastatic colorectal cancer. Int J Cancer. 2015;136(1):83-90. https://doi.org/10.1002/ ijc.28955.

23. Schirripa M, Bergamo F, Cremolini C, Casagrande M, Lonardi S, Aprile G, et al. BRAF and RAS mutations as prognostic factors in metastatic colorectal cancer patients undergoing liver resection. Br J Cancer. 2015;112(12):1921-8. https://doi.org/10.1038/bjc.2015.142.

24. Renaud S, Romain B, Falcoz PE, Olland A, Santelmo N, Brigand C, et al. KRAS and BRAF mutations are prognostic biomarkers in patients undergoing lung metastasectomy of colorectal cancer. Br J Cancer. 2015;112(4):720-8. https:// doi.org/10.1038/bjc.2014.499.

25. Takahashi M, Hasegawa K, Oba M, Aoki T, Sakamoto Y, Sugawara Y, et al. Repeat resection leads to long-term survival: analysis of 10-year follow-up of patients with colorectal liver metastases. Am J Surg. 2015;210(5):904-10. https://doi.org/10.1016/j.amjsurg.2015.01.026.

26. Adam R, Bismuth $H$, Castaing D, Waechter F, Navarro F, Abascal A, et al. Repeat hepatectomy for colorectal liver metastases. Ann Surg. 1997;225(1): 51-60 discussion -2

27. Oba M, Hasegawa K, Matsuyama Y, Shindoh J, Mise Y, Aoki T, et al. Discrepancy between recurrence-free survival and overall survival in patients with resectable colorectal liver metastases: a potential surrogate endpoint for time to surgical failure. Ann Surg Oncol. 2014;21(6):1817-24. https://doi. org/10.1245/s10434-014-3504-1.

28. Bellier J, De Wolf J, Hebbar M, Amrani ME, Desauw C, Leteurtre $E_{1}$ et al. Repeated resections of hepatic and pulmonary metastases from colorectal Cancer provide long-term survival. World J Surg. 2018;42(4):1171-9. https:// doi.org/10.1007/s00268-017-4265-3.

29. Mise Y, Zimmitti G, Shindoh J, Kopetz S, Loyer EM, Andreou A, et al. RAS mutations predict radiologic and pathologic response in patients treated with chemotherapy before resection of colorectal liver metastases. Ann Surg Oncol. 2015;22(3):834-42. https://doi.org/10.1245/s10434-014-4042-6.

30. Garcia-Carbonero N, Martinez-Useros J, Li W, Orta A, Perez N, Carames C, et al. KRAS and BRAF mutations as prognostic and predictive biomarkers for standard chemotherapy response in metastatic colorectal cancer: a single institutional study. Cells. 2020;9(1):219. https://doi.org/10.3390/cells9010219.

31. Margonis GA, Amini N, Andreatos N, Sasaki K, McVey J, Mirza MB, et al. KRAS mutational status impacts pathologic response to pre-hepatectomy chemotherapy: a study from the international genetic consortium for liver metastases. HPB (Oxford). 2019;21(11):1527-34. https://doi.org/10.1016/j. hpb.2019.03.368.

32. Kobayashi S, Beppu T, Honda G, Yamamoto M, Takahashi K, Endo I, et al. Survival benefit of and indications for adjuvant chemotherapy for resected colorectal liver metastases-a Japanese Nationwide survey. J Gastrointest Surg. 2019. 
33. Margonis GA, Sasaki K, Andreatos N, Kim Y, Merath K, Wagner D, et al. KRAS mutation status dictates optimal surgical margin width in patients undergoing resection of colorectal liver metastases. Ann Surg Oncol. 2017; 24(1):264-71. https://doi.org/10.1245/s10434-016-5609-1.

34. Brudvik KW, Mise Y, Chung MH, Chun YS, Kopetz SE, Passot G, et al. RAS mutation predicts positive resection margins and narrower resection margins in patients undergoing resection of colorectal liver metastases. Ann Surg Oncol. 2016;23(8):2635-43. https://doi.org/10.1245/s10434-016-5187-2.

35. Zhang Q, Peng J, Ye M, Weng W, Tan C, Ni S, et al. KRAS mutation predicted more Mirometastases and closer resection margins in patients with colorectal Cancer liver metastases. Ann Surg Oncol. 2020;27(4):1164-73. https://doi.org/10.1245/s10434-019-08065-5.

36. Nuzzo G, Giuliante F, Ardito F, Vellone M, Giovannini I, Federico B, et al. Influence of surgical margin on type of recurrence after liver resection for colorectal metastases: a single-center experience. Surgery. 2008;143(3):38493. https://doi.org/10.1016/j.surg.2007.09.038

37. Xu D, Wang HW, Yan XL, Li J, Wang K, Xing BC. Sub-millimeter surgical margin is acceptable in patients with good tumor biology after liver resection for colorectal liver metastases. Eur J Surg Oncol. 2019:45(9):1551-8. https://doi.org/10.1016/j.ejso.2019.03.010.

\section{Publisher's Note}

Springer Nature remains neutral with regard to jurisdictional claims in published maps and institutional affiliations.

Ready to submit your research? Choose BMC and benefit from:

- fast, convenient online submission

- thorough peer review by experienced researchers in your field

- rapid publication on acceptance

- support for research data, including large and complex data types

- gold Open Access which fosters wider collaboration and increased citations

- maximum visibility for your research: over $100 \mathrm{M}$ website views per year

At $\mathrm{BMC}$, research is always in progress.

Learn more biomedcentral.com/submissions 